\title{
Cyclophilin D-Sensitive Mitochondrial Permeability Transition in Adult Human Brain and Liver Mitochondria
}

\author{
Magnus J. Hansson,,2 Saori Morota, Li Chen, ${ }^{3}$ Nagahisa Matsuyama, ${ }^{4}$ Yoshiaki Suzuki, ${ }^{5}$ \\ Satoshi Nakajima, ${ }^{6}$ Tadashi Tanoue, ${ }^{7}$ Akibumi Omi, ${ }^{8}$ Futoshi Shibasaki, ${ }^{3}$ \\ Motohide Shimazu, ${ }^{5}$ Yukio Ikeda, ${ }^{6}$ Hiroyuki Uchino, ${ }^{9}$ and Eskil Elmér ${ }^{1,10}$
}

\begin{abstract}
The mitochondrial permeability transition $(\mathrm{mPT})$ is considered to be a major cause of cell death under a variety of pathophysiological conditions of the central nervous system (CNS) and other organs. Pharmacological inhibition or genetic knockout of the matrix protein cyclophilin $\mathrm{D}(\mathrm{CypD})$ prevents $\mathrm{mPT}$ and cell degeneration in several models of brain injury. If these findings in animal models are translatable to human disease, pharmacological inhibition of $\mathrm{mPT}$ offers a promising therapeutic target. The objective of this study was to validate the presence of a CypD-sensitive mPT in adult human brain and liver mitochondria. In order to perform functional characterization of human mitochondria, fresh tissue samples were obtained during hemorrhage or tumor surgery and mitochondria were rapidly isolated. Mitochondrial calcium retention capacity, a quantitative assay for $\mathrm{mPT}$, was significantly increased by the CypD inhibitor cyclosporin $\mathrm{A}$ in both human brain and liver mitochondria, whereas thiol-reactive compounds and oxidants sensitized mitochondria to calcium-induced mPT. Brain mitochondria underwent swelling upon calcium overload, which was reversible upon calcium removal. To further explore $\mathrm{mPT}$ of human mitochondria, liver mitochondria were demonstrated to exhibit several classical features of the $\mathrm{mPT}$ phenomenon, such as calcium-induced loss of membrane potential and respiratory coupling, as well as release of the pro-apoptotic protein cytochrome c. We concluded that adult viable human brain and liver mitochondria possess an active CypD-sensitive mPT. Our findings support the rationale of CypD and $\mathrm{mPT}$ inhibition as pharmacological targets in acute and chronic neurodegeneration.
\end{abstract}

Key words: ischemia; oxidative stress; mitochondria; traumatic brain injury; traumatic spinal cord injury

\section{Introduction}

A CTIVATION of mitochondrial permeability transition (MPT) is considered to be a major cause of cell death under a variety of pathophysiological conditions, including ischemia/reperfusion injury, neurodegenerative disease, traumatic brain injury (TBI), muscular dystrophy, and drug toxicity (Bernardi et al., 2006; Halestrap and Pasdois, 2009; Kroemer et al., 2007; Liu and Murphy, 2009; Mbye et al., 2009; Millay et al., 2008; Nicholls, 2009; Russmann et al., 2009). Provided that findings in animal models can be translated to human disease, pharmacological inhibition of $\mathrm{mPT}$ offers a promising therapeutic target for the treatment of these disorders (Baines, 2010; Cook et al., 2009; Morota et al., 2009; Waldmeier et al., 2003).

The $\mathrm{mPT}$ is defined as a sudden increase in inner mitochondrial membrane permeability causing loss of ion homeostasis and the proton motive force required for ATP synthesis. The matrix protein cyclophilin $\mathrm{D}(\mathrm{CypD})$ is a peptidylprolyl cis-trans isomerase that regulates $\mathrm{mPT}$ and facilitates its activation by calcium. Animals lacking CypD display increased resistance to ischemic insults, muscular dystrophies, multiple sclerosis, amyotrophic lateral sclerosis (ALS), and Alzheimer's disease (Baines et al., 2005; Du et al., 2008;

\footnotetext{
${ }^{1}$ Mitochondrial Pathophysiology Unit, Laboratory for Experimental Brain Research, Department of Clinical Sciences, Lund University, Lund, Sweden.

${ }^{2}$ Department of Clinical Physiology, and ${ }^{10}$ Department of Clinical Neurophysiology, Skåne University Hospital, Lund, Sweden.

${ }^{3}$ Department of Molecular Cell Physiology, Tokyo Metropolitan Institute of Medical Science, Tokyo, Japan.

${ }^{4}$ Department of Pathology, ${ }^{5}$ Department of Surgery, and ${ }^{9}$ Department of Anesthesiology, Tokyo Medical University, Tokyo, Japan.

${ }^{6}$ Department of Neurosurgery, Tokyo Medical University, Hachioji Medical Center, Tokyo, Japan.

${ }^{7}$ Department of Anesthesiology, Kumamoto Regional Medical Center, Kumamoto, Japan.

${ }^{8}$ Department of Anesthesiology, Kosei Chuoh Hospital, Tokyo, Japan.
} 
Forte et al., 2007; Martin et al., 2009; Nakagawa et al., 2005; Schinzel et al., 2005), and the CypD inhibitor cyclosporin A (CsA) and its analogs have displayed neuroprotective effects in several animal models of acute neurological damage and chronic neurodegenerative disease. CsA treatment has also demonstrated promising results in initial clinical trials of TBI (Empey et al., 2006; Hatton et al., 2008; Mazzeo et al., 2008), as well as myocardial reperfusion injury (Mewton et al., 2010; Piot et al., 2008). Preserving the integrity of mitochondrial membranes through inhibition of $\mathrm{mPT}$ has been put forward as the central mechanism for the neuroprotective and cardioprotective effects of CsA, even though the drug has several pharmacological targets. Further, it has not been established whether cellular calcium overload and oxidative stress can trigger the $\mathrm{MPT}$ phenomenon in adult human mitochondria similarly to that described in mitochondria derived from animal tissues. It has also been suggested that $\mathrm{CypD}$ is downregulated in neurons during development, which would decrease the sensitivity of the $\mathrm{mPT}$ to calcium, and prohibit the use of $\mathrm{CypD}$ as a pharmacological target in disorders of the adult central nervous system (CNS) (Eliseev et al., 2007).

The purpose of this study was to determine whether a CypD-sensitive $\mathrm{mPT}$ exists in adult human brain and liver mitochondria, and thus constitutes a relevant pharmacological target in diseases for which $\mathrm{mPT}$ has been implicated in the pathogenesis. Further, if present, the objective was to evaluate whether human $\mathrm{mPT}$ displays analogous functional characteristics and is modulated by endogenous regulators and oxidants similarly to mitochondria from animal tissues.

\section{Methods}

\section{Tissue samples}

In order to obtain fresh human tissue for functional mitochondrial analyses, brain samples were collected from five patients undergoing neurosurgery, and liver tissue from seven patients undergoing liver resection (see Table 1 for patient demographics). Tissue that would otherwise have been discarded was transferred into ice-cold isolation buffer and rapidly prepared for mitochondrial isolation. Only the morphologically normal parenchyma surrounding the resected tumors was used. The human study was approved by the Ethical Committee of Hachioji Medical Center, Tokyo Medical University, permit number 12-01, and complied with the World Medical Association Declaration of Helsinki Ethical
Principles for Medical Research Involving Human Subjects, and the EU Convention for the Protection of Human Rights and Dignity of the Human Being with Regard to the Application of Biology and Medicine: Convention on Human Rights and Biomedicine.

\section{Mitochondrial isolation}

Isolation of human brain mitochondria was achieved using a discontinuous Percoll gradient according to the method of Sims and Anderson (Sims and Anderson, 2008), with slight modification as previously described (Hansson et al., 2008), and the three density gradient layers consisted of $12 \%, 19 \%$, and $40 \%$ Percoll, respectively. Liver mitochondria were isolated using differential centrifugation including a 19\% Percoll step (Hansson et al., 2008).

\section{Mitochondrial permeability transition assays}

A Perkin-Elmer luminescence spectrometer (LS-55B; Emeryville, CA) with a temperature-controlled cuvette holder was used for all fluorescence and light scattering experiments. De-energized experiments were performed at $28^{\circ} \mathrm{C}$ in a $150 \mathrm{mM} \mathrm{KCl}$-based buffer containing $0.5 \mu \mathrm{M}$ rotenone, $0.2 \mathrm{mg} / \mathrm{mL}$ antimycin $\mathrm{A}, 2 \mu \mathrm{M}$ calcium ionophore A23187, 0.5 mM PPi, and $2 \mathrm{mM}$ nitrilotriacetic acid. Swelling and calcium retention capacity (CRC) experiments using respiring mitochondria were performed at $37^{\circ} \mathrm{C}$ in a $125 \mathrm{mM}$ KCl-based buffer, including $2 \mathrm{mM} \mathrm{Pi}(\mathrm{K}), 200 \mu \mathrm{M}$ ATP, $50 \mu \mathrm{M}$ $\mathrm{ADP}, 1 \mathrm{mM} \mathrm{MgCl} 2,5 \mathrm{mM}$ malate, and $5 \mathrm{mM}$ glutamate. The extent of swelling was calculated as the calcium-induced decrease in light scattering compared to that by the ionophore alamethicin $(10 \mu \mathrm{g} / \mathrm{mL}$; Hansson et al., 2004a). Due to some variability between mitochondrial preparations, the $\mathrm{Ca}^{2+}$ concentrations administered to the mitochondrial suspensions ranged from 80 to $150 \mu \mathrm{M}$, to reach a comparable inter-experimental control response. The same concentration was used for all experiments of a particular preparation. Mitochondrial calcium uptake and release were monitored by the excitation ratio (ex. $340 / 380 \mathrm{~nm}$, em. $509 \mathrm{~nm})$ of the extramitochondrial calcium-sensitive fluorescent probe Fura $6 \mathrm{~F}(250 \mathrm{nM})$. The brain mitochondrial suspensions were infused with $77-200 \mathrm{nmol} \mathrm{CaCl}_{2} /$ $(\mathrm{mg} \times \mathrm{min})$. In one set of experiments (Fig. 1B), the infusion speed was initially at the lowest range, but then doubled following infusion of $2.5 \mu \mathrm{mol} / \mathrm{mg} \mathrm{CaCl}{ }_{2}$ in order to reduce

Table 1. Patient Demographics, Indications for Surgery, and Origin of Tissue Samples

\begin{tabular}{llcll}
\hline Brain $(B)$ or liver $(L)$ sample & Gender & Age $(y)$ & Indication for surgery & Origin of tissue \\
\hline B1 & Male & 45 & Arteriovenous malformation & Right temporal cortex \\
B2 & Male & 72 & Intracerebral hemorrhage & Caudate putamen \\
B3 & Male & 42 & Subarachnoid hemorrhage & Right frontal cortex \\
B4 & Male & 81 & Intracerebral hemorrhage & Right frontal cortex \\
B5 & Male & 62 & Glioma & Right temporal cortex \\
L1 & Male & 58 & Metastatic colon cancer & Quadrate lobe \\
L2 & Male & 60 & Metastatic colon cancer & Quadrate lobe \\
L3 & Male & 65 & Metastatic colon cancer & Left lateral segment \\
L4 & Male & 57 & Metastatic colon cancer & Left lateral segment \\
L5 & Male & 56 & Bile duct cancer & Quadrate lobe \\
L6 & Female & 80 & Metastatic liver carcinoma & Quadrate lobe \\
L7 & Female & 74 & Metastatic liver carcinoma & Quadrate lobe \\
\hline
\end{tabular}


experimental time. Liver mitochondria were infused with $50 \mathrm{nmol} \mathrm{CaCl}_{2} /(\mathrm{mg} \times \mathrm{min})$. CRC was calculated as the amount of infused calcium from the start of mitochondrial calcium uptake, until start of maximal calcium release. Rhodamine $123(100 \mathrm{nM})$ was used to assess mitochondrial membrane potential, with excitation and emission set to $490 \mathrm{~nm}$ and $528 \mathrm{~nm}$, respectively.

\section{Mitochondrial respiration}

Respiratory activities of mitochondrial preparations were measured by determining oxygen consumption in airtight chambers at $30^{\circ} \mathrm{C}$, using Clark-type oxygen electrodes (Hansatech, Norfolk, U.K.). First, $100 \mu \mathrm{g}$ brain or $200 \mu \mathrm{g}$ liver mitochondria were suspended in $400 \mu \mathrm{L}$ respiration medium consisting of $5 \mathrm{mM}$ malate, $5 \mathrm{mM}$ glutamate, $110 \mathrm{mM}$ sucrose, $60 \mathrm{mM}$ K-lactobionate, $0.5 \mathrm{mM}$ EGTA, $1 \mathrm{~g} / \mathrm{L} \mathrm{BSA}, 3 \mathrm{mM}$ $\mathrm{MgCl}_{2}, 20 \mathrm{mM}$ taurine, $10 \mathrm{mM}$ Pi (K), and $20 \mathrm{mM} \mathrm{K}-\mathrm{HEPES}$ (pH 7.1; Kuznetsov et al., 2004). Respiratory control ratios (RCR) were calculated as the ratio of oxygen consumption during active phosphorylation in the presence of ADP (state 3 ) to the resting rate after ADP was consumed (state 4), or after addition of $1 \mu \mathrm{g} / \mathrm{mL}$ oligomycin (state $4_{\text {oligo }}$ ).

\section{Electron microscopy}

Mitochondrial samples were immersed in $2.5 \%$ glutaraldehyde in phosphate buffer $(\mathrm{pH}$ 7.4) for $2 \mathrm{~h}$, washed in phosphate buffer for $20 \mathrm{~min}$, immersed for $2 \mathrm{~h}$ in $1 \%$ osmium tetroxide in phosphate buffer, and then dehydrated with graded alcohol and embedded with embedding medium. Sections $50 \mathrm{~nm}$ in size were prepared in Reichert-Jung Ultracut-E and stained with $4 \%$ uranylacetate, followed by $0.5 \%$ lead citrate. Electron micrographs were obtained using a Hitachi H-7000 electron microscope (Hitachi Ltd., Tokyo, Japan).

\section{Cytochrome c release}

Liver mitochondrial samples were prepared similarly to the light scattering experiments, and were exposed to $200 \mu \mathrm{M}$ $\mathrm{Ca}^{2+}$ with or without mPT inhibitors. An ELISA kit for detection of human cytochrome c (Cyt c; Quantikine ${ }^{\circledR} ; \mathrm{R} \& \mathrm{D}$ Systems, Inc., Minneapolis, MN) was employed to measure Cyt c release as described previously (Hansson et al., 2008).

\section{Immunoblotting}

Samples of isolated mitochondria were boiled with $2 \times$ SDS sample buffer for $10 \mathrm{~min}$. Total protein (12-24 $\mu \mathrm{g} / \mathrm{sample})$ was separated on 4-12\% NuPAGE gels (Invitrogen, Carlsbad, CA), transferred to PVDF membranes, and blocked overnight with 5\% skim milk in phosphate-buffered saline. A laboratory-generated (F. Shibazaki), and a commercial (PA1-028; Pierce Thermo Fischer Scientific, Rochester, NY), primary rabbit polyclonal antibody against human $\mathrm{CypD}$ were used. Anti-tubulin antibody (Sigma-Aldrich, St. Louis, MO), and anti-ANT mouse monoclonal antibody (Calbiochem, San Diego, CA) were used for internal control. The primary antibodies were incubated at room temperature for $1 \mathrm{~h}$. Antihorseradish peroxidase (HRP)-conjugated anti-rabbit or antimouse IgG secondary antibodies (Pierce Thermo Fischer Scientific) were incubated at room temperature for $1 \mathrm{~h}$, and then washed six times with phosphate-buffered saline containing $0.1 \%$ Tween 20 , and detected on Western blots by the
SuperSignal West Dura chemiluminescence detection system (Pierce Thermo Fischer Scientific).

\section{Statistical analysis}

All liver mitochondrial experiments were replicated in at least 3-4 separate mitochondrial preparations. Data are presented as means \pm standard error of the mean (SEM), and were generally evaluated with analysis of variance (ANOVA), followed by Dunnett's post-hoc test. Paired comparisons were performed for CRC experiments, as all evaluations of treatment effects were performed using mitochondria from the same individuals. The effect of $\mathrm{CypD}$ inhibition on brain mitochondrial CRC was evaluated in four, and reversible swelling in three, separate preparations. The level of statistical significance was set at 5\%. Other swelling experiments, respiration, and CRC experiments for phenylarsine oxide were only replicated in two separate brain mitochondrial preparations due to limited size of the samples, and no statistical analyses were performed.

\section{Results \\ Mitochondrial permeability transition \\ in human brain and liver mitochondria is modulated by cyclophilin $D$ and oxidative stress}

The isolation procedure resulted in a yield of $0.13-0.97 \mathrm{mg}$ brain mitochondria and $2.4-21 \mathrm{mg}$ liver mitochondria from the different tissue samples $(0.13-0.95 \mathrm{~g}$ brain tissue and $0.4-$ $3.9 \mathrm{~g}$ liver tissue). Due to the restricted availability and variation in the amount of utilizable brain tissue obtained, we were unable to do full sets of experiments on the brain mitochondrial preparations. To investigate the presence of $\mathrm{mPT}$ in adult human mitochondria, suspensions of brain and liver mitochondria were exposed to continuous infusions of calcium, and CRC was determined. CRC is a quantitative $\mathrm{mPT}$ assay that measures the amount of calcium mitochondria can retain before induction of $\mathrm{mPT}$ causes release of the sequestered calcium (Chalmers and Nicholls, 2003; Hansson et al., 2010). In a physiological medium containing adenine nucleotides and $\mathrm{P}_{\mathrm{i}}$, the CypD inhibitor CsA significantly increased CRC in both brain $\left(2.34 \pm 0.23\right.$ and $2.99 \pm 0.34 \mu \mathrm{mol} \mathrm{Ca}{ }^{2+} / \mathrm{mg}$ mitochondria, for control and $1 \mu \mathrm{M} \mathrm{CsA}$, respectively), and liver mitochondria $\left(1.02 \pm 0.27\right.$ and $1.51 \pm 0.20 \mu \mathrm{mol} \mathrm{Ca}^{2+} / \mathrm{mg}$ mitochondria, for control and $1 \mu \mathrm{M}$ CsA, respectively; Fig. 1A-D). Immunoblots confirmed the presence of CypD in the isolated mitochondrial preparations (Fig. 1E). Oxidative stress is considered to sensitize mitochondria to $\mathrm{mPT}$ activation through oxidation of critical thiol groups on the $\mathrm{MPT}$ pore components (Halestrap et al., 1997; Petronilli et al., 1994). The vicinal thiol reagent phenylarsine oxide (PhArs; $1 \mu \mathrm{M}$ ) demonstrated a clear tendency toward reduced CRC in brain mitochondria (Fig. 1C, $n=2$ ), and a significant reduction of $\mathrm{CRC}$ in liver mitochondria $\left(0.39 \pm 0.16 \mu \mathrm{mol} \mathrm{Ca}{ }^{2+} / \mathrm{mg}\right.$; Fig. $1 \mathrm{D}, n=3)$. The oxidant tert-butyl hydroperoxide (tBOOH; $500 \mu \mathrm{M})$ also significantly reduced CRC in liver mitochondria $\left(0.79 \pm 0.22 \mu \mathrm{mol} \mathrm{Ca}{ }^{2+} / \mathrm{mg} ;\right.$ Fig. 1D).

\section{Loss of respiratory coupling following calcium-induced permeability transition}

In order to assess the functional integrity of isolated mitochondrial preparations, respiration experiments were performed. Both brain and liver mitochondria demonstrated 

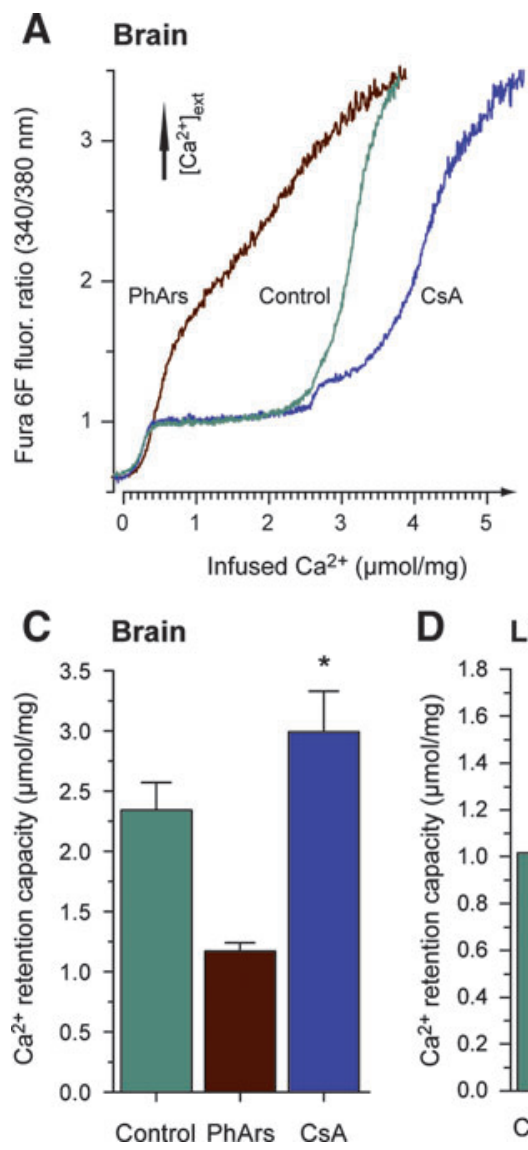

B Liver

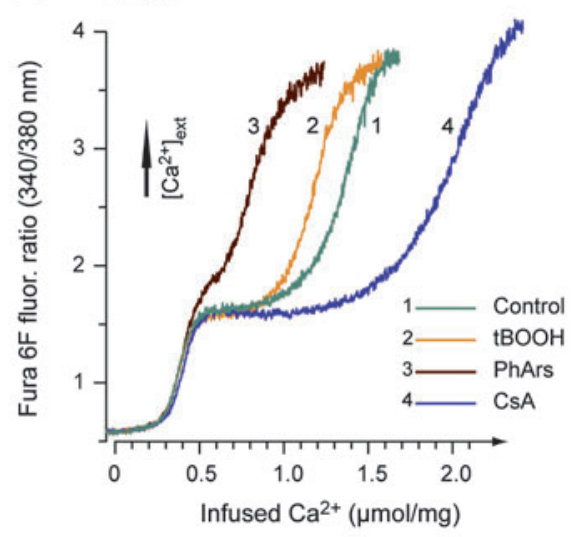

E
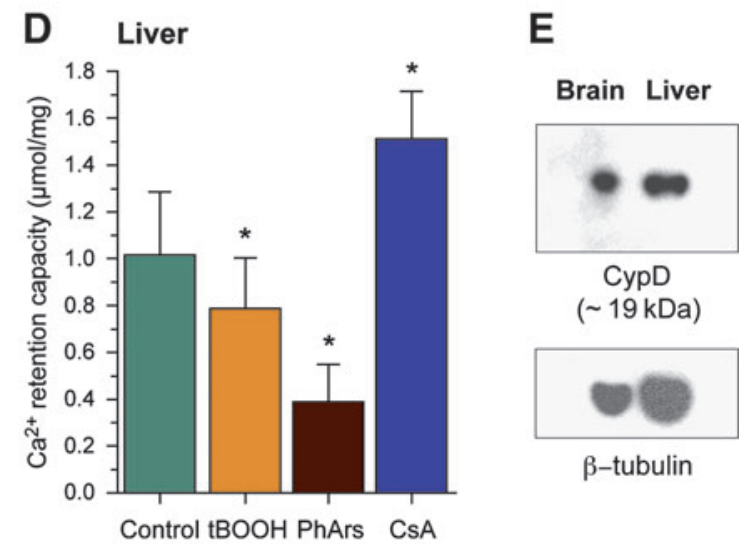

FIG. 1. Modulation of calcium retention capacity in human brain and liver mitochondria by cyclophilin $\mathrm{D}(\mathrm{CypD})$ inhibition and oxidants. (A and B) Representative traces of human brain and liver mitochondrial calcium handling during continuous calcium infusion. Changes in fura $6 \mathrm{~F}$ fluorescence intensity correspond to the level of extramitochondrial $\left[\mathrm{Ca}^{2+}\right]$. Experiments were performed with or without presence of the CypD-inhibitor cyclosporin A (CsA, $1 \mu \mathrm{M})$, the vicinal thiol reagent phenylarsine oxide (PhArs, $1 \mu \mathrm{M}$ ), and tert-butyl hydroperoxide (tBOOH, $500 \mu \mathrm{M}$, tested in liver mitochondria only). (C and D) Calculated mitochondrial calcium retention capacity. Values are means \pm standard error of the mean (SEM; ${ }^{*}$ in $\mathrm{C}$ indicates $p<0.05$ by paired $t$-test, $n=4$ for control and CsA; PhArs was only tested twice in brain mitochondria and no statistical evaluation was performed; * in $\mathbf{D}$ indicates $p<0.05$ by repeated-measures ANOVA with Dunnett's post-hoc test, $n=3)$. (E) Western blots of CypD and $\beta$-tubulin in isolated human brain and liver mitochondria (12 $\mu \mathrm{g} / \mathrm{lane}$ and $22 \mu \mathrm{g} / \mathrm{lane}$ were used for brain and liver mitochondria, respectively).

well-coupled respiration (Fig. 2). Mean respiratory control ratios (RCR) of liver mitochondria were $5.28 \pm 0.59$ and $9.92 \pm 1.2$ for state $3 /$ state $4(n=5)$, and state $3 /$ state $4_{\text {oligo }}$ $(n=4)$, respectively. Brain mitochondria demonstrated an RCR of 3.9 in one complete experiment (Fig. 2A), and 12.6 in a second experiment with a lower concentration of mitochondria (which tended to overestimate the ratio; data not shown). Following exposure to $\mathrm{Ca}^{2+}$, liver mitochondria demonstrated respiratory inhibition and loss of respiratory coupling, as evidenced by a lack of stimulatory responses upon addition of ADP or the protonophore CCCP (carbonyl cyanide mchlorophenylhydrazone) (Fig. 2B).

\section{Inhibition of calcium-induced swelling, membrane potential loss, and Cyt c release by cyclosporin analogs and adenine nucleotides in human liver mitochondria}

To further evaluate the presence and characteristics of $\mathrm{mPT}$ in human mitochondria, mitochondrial morphology, membrane potential, and Cyt $c$ release were examined following calcium exposure. Without cyclosporin analogs present, calcium induced an extensive degree of mitochondrial swelling, $69.0 \pm 6.3 \%$ compared to that of the non-specific ionophore alamethicin, and mitochondrial membrane potential was essentially lost (Fig. 3A-C). Electron micrographs confirmed a dramatic change in mitochondrial morphology following calcium exposure, including matrix swelling and disruption of the outer mitochondrial membrane (Fig. 3D). The CypD inhibitor CsA, and the non-immunosuppressive cyclosporin analog D-MeAla ${ }^{3}$ $\mathrm{EtVal}^{4}$-cyclosporin (NI-Cs), virtually abolished the calciuminduced swelling $(3.67 \pm 7.1 \%$ and $5.94 \pm 12.1 \%$, respectively; Fig. 3A and C), and largely prevented the loss of membrane potential (Fig. 3B). Electron micrographs of mitochondria exposed to calcium in the presence of CsA did not display any overt morphological alterations (Fig. 3D). Calcium exposure also induced an extensive Cyt $\mathrm{c}$ release $(37.1 \pm 3.1 \%$ and $8.43 \pm 3.8 \%$ of total Cyt c content for mitochondria with and without $200 \mu \mathrm{M} \mathrm{Ca}^{2+}$, respectively; 
$p<0.05)$, which was significantly inhibited by ADP and CsA (14.2 $\pm 1.2 \%$ of total Cyt c content; Fig. 3E).

In de-energized mitochondria calcium-induced $\mathrm{MPT}$ is independent of respiration-driven electrophoretic $\mathrm{Ca}^{2+}$ uptake, as the anion equilibrates over the mitochondrial inner membrane through a calcium ionophore, and more direct pharmacological interactions with the components of the mPT pore complex can be studied. The CypD inhibitors CsA and NI-Cs (both at $1 \mu \mathrm{M}$ ), as well as the adenine nucleotides ADP and ATP (both at $100 \mu \mathrm{M}$ ), almost completely prevented the

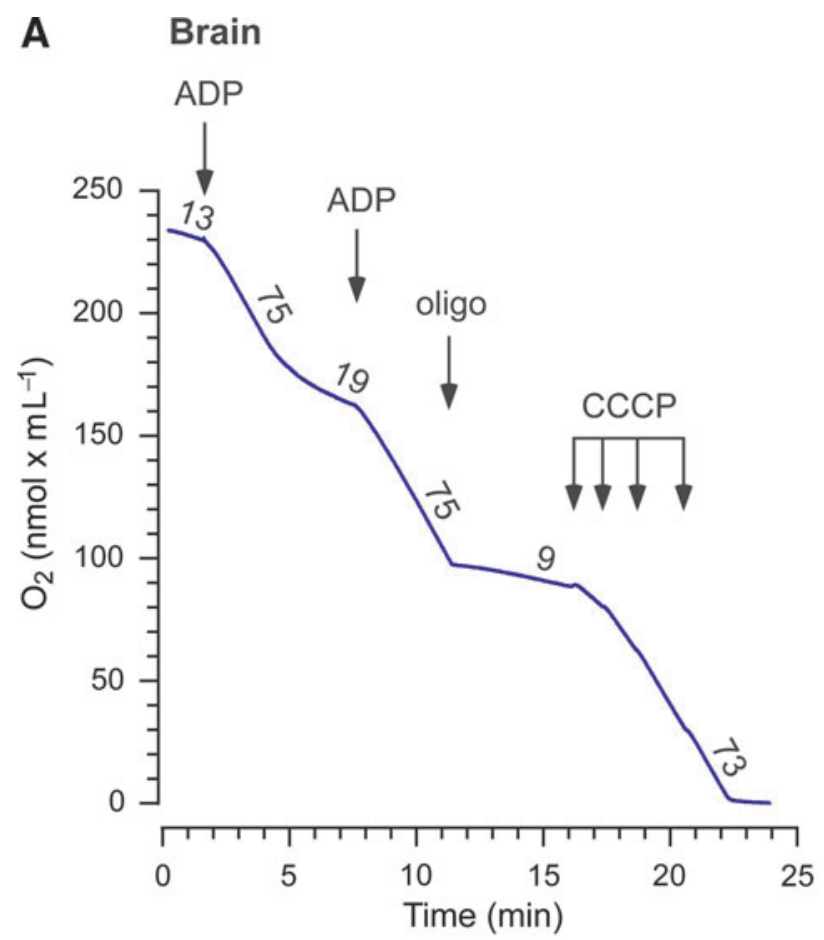

B Liver

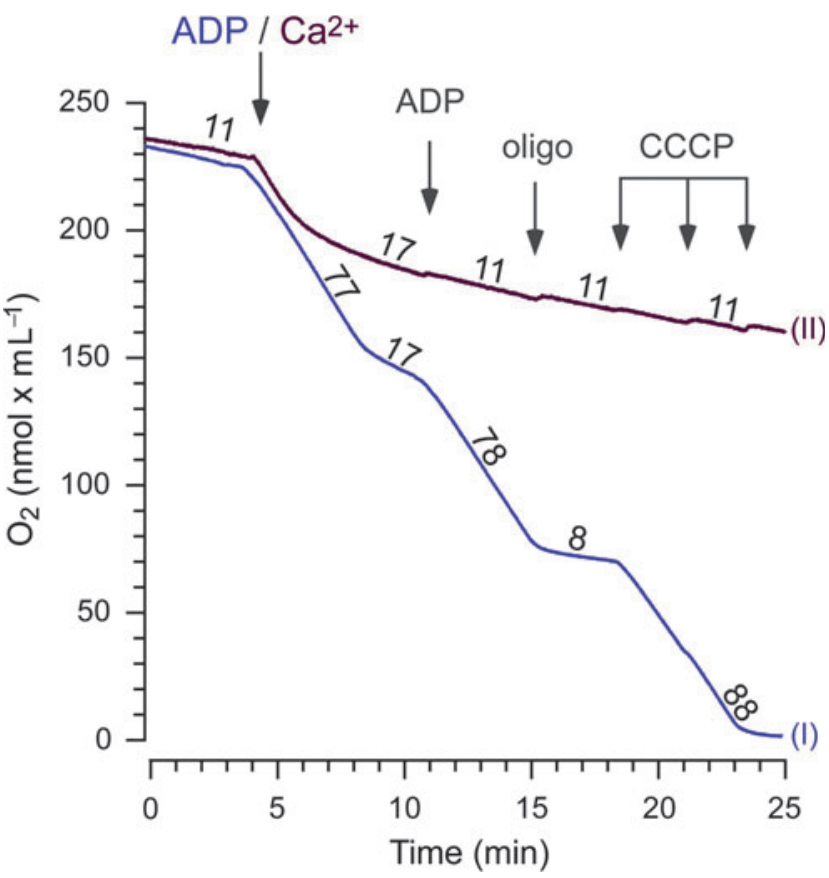

swelling induced by $200 \mu \mathrm{M} \mathrm{Ca}^{2+}$ in de-energized liver mitochondria (Fig. $4 \mathrm{~A}$ and B).

\section{Reversible calcium-induced swelling and inhibition of swelling by MPT modulators in human brain mitochondria}

To explore the characteristics of mPT-mediated swelling in human brain mitochondria, the samples were exposed to either transient or long-term calcium exposure. In one set of experiments, $200 \mu \mathrm{M} \mathrm{Ca}^{2+}$ was administered to mitochondria, EGTA was added after $1 \mathrm{~min}$ to chelate the calcium, and the initial light-scattering decrease by calcium was significantly reversed, from $33.9 \pm 5.2 \%$ to $15.9 \pm 4.1 \%$ (of alamethicininduced swelling, $n=3$; Fig. 5A). The mitochondria also underwent a pronounced swelling response following a second calcium addition. In another set of experiments human brain mitochondria were exposed to calcium with or without presence of $1 \mu \mathrm{M} \mathrm{CsA}$ and $100 \mu \mathrm{M}$ ADP. The mPT modulators delayed and partially prevented the swelling response following an addition of a total of $200 \mu \mathrm{M} \mathrm{Ca}^{2+}(n=2$, no statistical analysis was performed; Fig. 5B).

\section{Discussion}

Mitochondrial dysfunction and activation of $\mathrm{mPT}$ are thoroughly implicated in several disorders of the CNS and other organs. Here we demonstrate that both human brain and liver mitochondria exhibit several classical characteristics of the mPT phenomenon following calcium overload. A number of previous conclusions on $\mathrm{mPT}$ drawn from animal studies are thus validated in adult human brain and liver mitochondria.

The molecular basis of $\mathrm{mPT}$ has been a matter of debate for a couple of decades and has yet to be fully resolved. Seminal studies by Hunter and Haworth established that MPT was induced by $\mathrm{Ca}^{2+}$ and inhibited by ADP, NADH, and $\mathrm{Mg}^{2+}$, and they suggested that MPT may be caused by the regulated opening of a non-specific channel (Haworth and Hunter, 1979; Hunter and Haworth, 1979a). Several lines of evidence pointed toward adenine nucleotide translocator (ANT) as the inner mitochondrial membrane protein mediating $\mathrm{mPT}$

FIG. 2. Coupled respiration in isolated human brain and liver mitochondria with respiratory inhibition following calcium-induced permeability transition. (A and B) Respiratory control was evaluated by measuring oxygen consumption of mitochondria oxidizing $5 \mathrm{mM}$ malate and glutamate during and after ADP phosphorylation (250 $\mu \mathrm{M}$ ADP). A second addition of ADP $(1 \mathrm{mM})$ was followed by administration of the ATP synthase inhibitor oligomycin (oligo, $1 \mu \mathrm{g} / \mathrm{mL}$ ), and titration of the protonophore CCCP, $0.5 \mu \mathrm{M}$ per addition. In liver mitochondria, the first ADP addition (trace I) was replaced by $1 \mathrm{mM} \mathrm{CaCl}_{2}$ (trace II) to induce $\mathrm{mPT}$. Calcium induced an initial stimulation of respiration, followed by respiratory inhibition and abolished respiratory control. The numbers indicate rates of respiration $\left[\mathrm{nmol} \mathrm{O}_{2} /(\mathrm{min} \times \mathrm{mg}\right.$ mitochondria)] from one experiment in brain mitochondria, and means from 4-5 experiments in liver mitochondria (CCCP, carbonyl cyanide $\mathrm{m}$-chlorophenylhydrazone; ADP, adenosine diphosphate; ATP, adenosine triphosphate; $\mathrm{CaCl}_{2}$, calcium chloride; $\mathrm{mPT}$, mitochondrial permeability transition). Color image is available online at www.liebertpub.com/neu. 

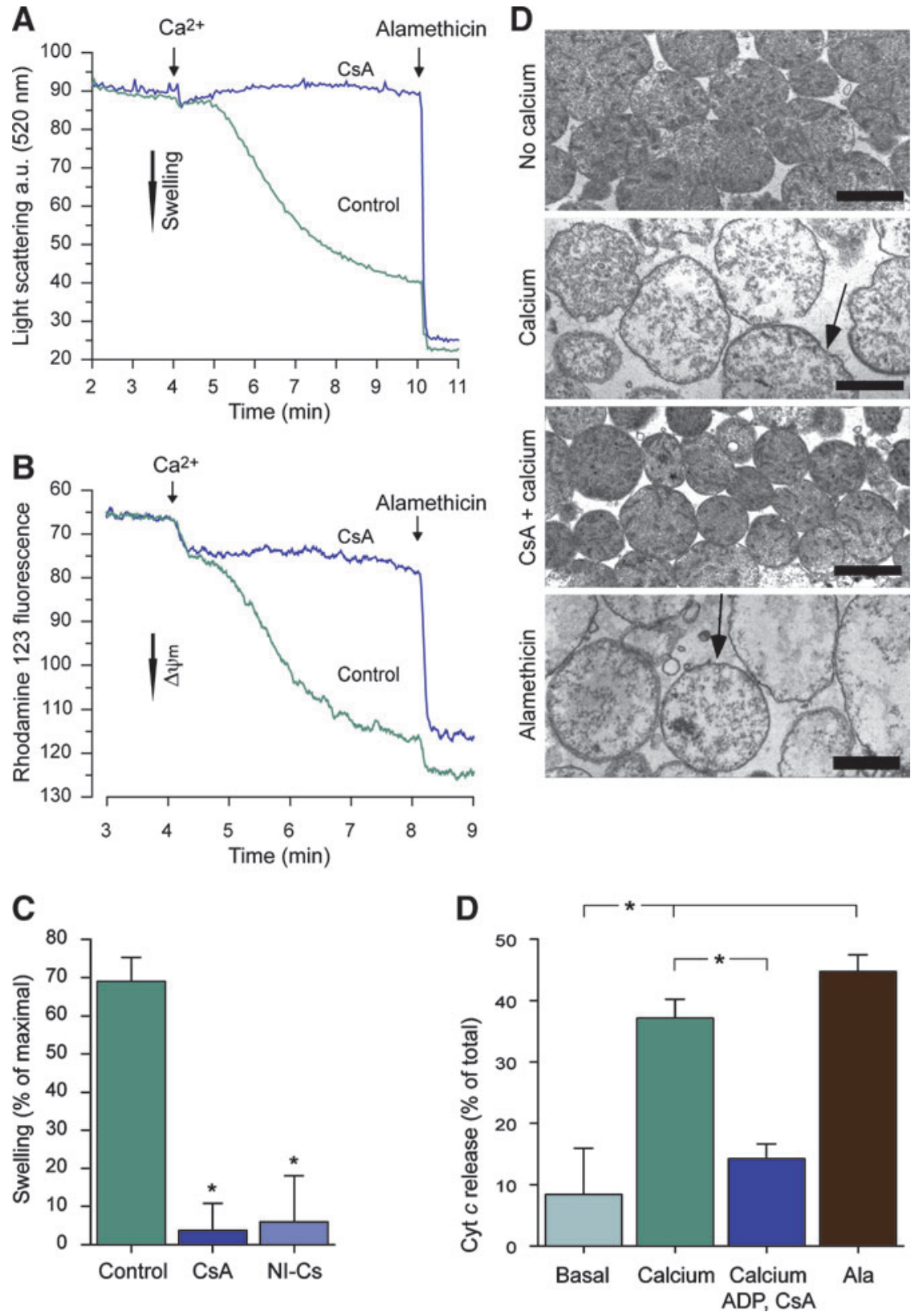

FIG. 3. Cyclophilin D (CypD)-sensitive swelling, membrane potential dissipation, and cytochrome c release in human liver mitochondria. Respiring human liver mitochondria were exposed to $100 \mu \mathrm{M} \mathrm{Ca}^{2+}$ with or without the presence of CypD inhibitors, and were monitored by following changes in (A) light scattering, or (B) rhodamine 123 fluorescence. Representative traces of control runs and experiments using the CypD inhibitor cyclosporin A (CsA; $1 \mu \mathrm{M})$ are shown. (C) The degree of calciuminduced mitochondrial swelling compared to that induced by the ionophore alamethicin (expressed as a percentage of maximal) was calculated from light-scattering traces for control, CsA, and for the non-immunosuppressive cyclosporin analog D-MeA$\mathrm{la}^{3} \mathrm{EtVal}^{4}$-cyclosporin (NI-Cs; $1 \mu \mathrm{M}$ ), using $80-150 \mu \mathrm{M} \mathrm{Ca}^{2+}$ to induce permeability transition $\left({ }^{*} p<0.05\right.$ compared to control by analysis of variance [ANOVA] with Dunnett's post-hoc test, $n=3-4)$. (D) Electron micrographs prepared from light-scattering experiments demonstrating gross morphological swelling and disruption of the outer mitochondrial membrane induced by $\mathrm{Ca}^{2+}$ (arrows). A similar appearance is seen following alamethicin exposure. In presence of CsA, no apparent morphological change was induced by $\mathrm{Ca}^{2+}$ (scale bars $\left.=1 \mu \mathrm{m}\right)$. (E) Cytochrome c (Cyt c) release from mitochondria incubated in medium only (control), exposed to $200 \mu \mathrm{M} \mathrm{Ca}^{2+}$ with or without the mPT inhibitors ADP $(200 \mu \mathrm{M})$ and CsA $(1 \mu \mathrm{M})$, and following alamethicin permeabilization ${ }^{*} p<0.05$ between groups by ANOVA with Bonferroni's post-hoc test, $n=4$; ADP, adenosine diphosphate; mPT, mitochondrial permeability transition; a.u., arbitrary units). Color image is available online at www.liebertpub.com/neu.

(Bauer et al., 1999; Brustovetsky and Klingenberg, 1996; Halestrap and Davidson, 1990; Hunter and Haworth, 1979a). The immunosuppressant CsA was later found to inhibit mPT activation (Crompton et al., 1988), and the effect was attributed to inhibition of the matrix peptidylprolyl cis-trans isomerase CypD, and its interaction with the inner membrane component of mPT (Halestrap and Davidson, 1990). Genetic knockout studies have confirmed an important regulatory 
A
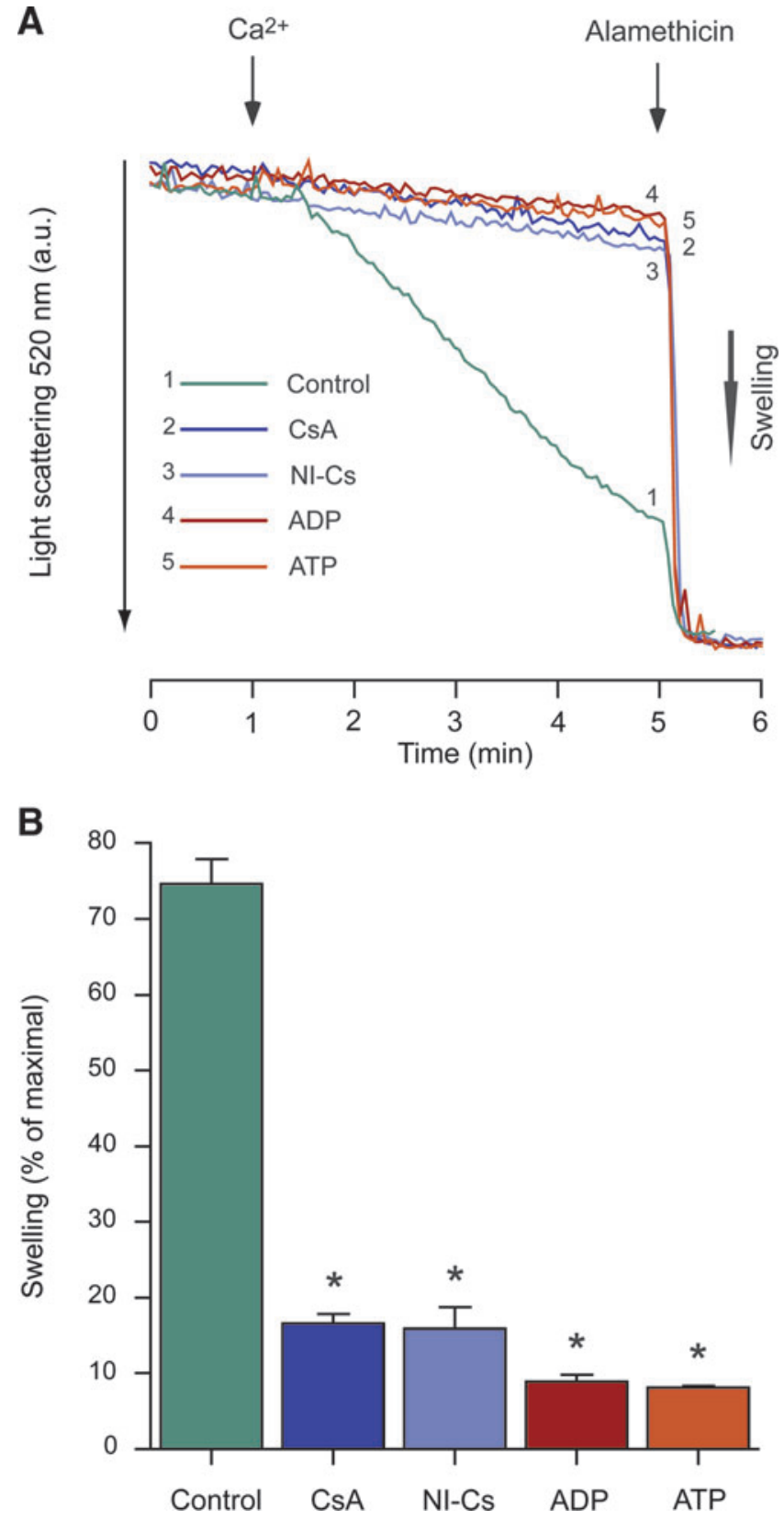

FIG. 4. Inhibition of permeability transition by cyclosporin analogs and adenine nucleotides in human liver mitochondria. (A) Representative traces of light-scattering changes of human liver mitochondria exposed to $200 \mu \mathrm{M} \mathrm{Ca}^{2+}$ under de-energized conditions, in presence of the cyclophilin $\mathrm{D}$ (CypD) inhibitors cyclosporin A $(\mathrm{CsA} ; 1 \mu \mathrm{M})$, or D-MeA$\mathrm{la}^{3} \mathrm{EtVal}^{4}$-cyclosporin (NI-Cs; $1 \mu \mathrm{M}$ ), or the endogenous mPT modulators ADP or ATP (both at $100 \mu \mathrm{M}$ ). (B) Calculations of swelling relative to that induced by alamethicin (percentage of maximal; ${ }^{*} p<0.05$ compared to control by analysis of variance with Dunnett's post-hoc test, $n=3$; ADP, adenosine diphosphate; ATP, adenosine triphosphate; $\mathrm{mPT}$, mitochondrial permeability transition; a.u., arbitrary units).

role of CypD and ANT, but have questioned that ANT is essential for $\mathrm{mPT}$ pore formation (Baines et al., 2005; Basso et al., 2005; Kokoszka et al., 2004; Nakagawa et al., 2005; Schinzel et al., 2005). Recent evidence has also suggested a role of the phosphate carrier in $\mathrm{mPT}$ pore formation and regulation (Alcala et al., 2008; Leung et al., 2008), but this awaits the close evaluation that has been performed for ANT and CypD. The present results demonstrate that both human brain and liver mitochondria exhibit several defining characteristics of the MPT phenomenon, such as calcium-induced swelling and calcium-induced calcium release. Human liver mitochondria also demonstrated calcium-induced loss of membrane potential and respiratory coupling, as well as release of Cyt c. These processes were repressed by CypD inhibitors and adenine nucleotides, supporting important roles of $\mathrm{CypD}$ and ANT in $\mathrm{mPT}$ activation in human mitochondria. Further, oxidative stress is considered to sensitize rodent mitochondria to $\mathrm{MPT}$ activation through oxidation of critical thiol groups on the $\mathrm{mPT}$ pore components (Halestrap et al., 1997; Petronilli et al., 1994), and both PhArs and tBOOH sensitized human liver mitochondria to $\mathrm{MPT}$.

Corresponding to the intricate regulation of $\mathrm{mPT}$, several classes of drugs have been shown or suggested to inhibit $\mathrm{mPT}$ (Kroemer et al., 2007; Zoratti and Szabo, 1995). One difficulty when attributing pharmacological effects to $\mathrm{mPT}$ inhibition is that drug effects are often non-specific, both at the mitochondrial level and in vivo (Morota et al., 2009). Another obstacle is that a seemingly beneficial effect on certain $\mathrm{MPT}$ characteristics may be caused by inhibition of otherwise vital mitochondrial functions, and the net outcome on mitochondrial integrity may be negative (Mansson et al., 2010). The most common evidence for $\mathrm{mPT}$ as a mediator of cell death, and thus its potential as a pharmacological target, derives from studies using CypD inhibitors such as CsA. Even though the target of CsA in mitochondria is specific, in contrast to several other proposed $\mathrm{mPT}$ inhibitors (Mansson et al., 2010; Morota et al., 2009), the effect in vivo is not. In order to determine the possible contribution of calcineurin inhibition to the effect of CsA, non-immunosuppressive cyclosporin analogs have been used, but they also inhibit other cyclophilins throughout the cell (Hansson et al., 2004b; Matsumoto et al., 1999; Mbye et al., 2009). A second obstacle when evaluating this class of drugs for neuroprotection is their limited penetration across the blood-brain barrier (BBB; Tsuji et al., 1993), unless measures are taken to facilitate CNS entry. Nevertheless, CsA and its analogs have been among the most convincing and broadly effective group of drugs displaying neuroprotective properties in several diverse models of acute and chronic neurological disease. Pharmacological studies using CypD inhibitors in animal models have in particular implicated $\mathrm{mPT}$ in the pathogenesis of focal and global ischemia (Domanska-Janik et al., 2004; Matsumoto et al., 1999; Uchino et al., 1998; Yoshimoto and Siesjö, 1999), hypoglycemic brain damage (Friberg et al., 1998), TBI (Buki et al., 1999; Mbye et al., 2009; Sullivan et al., 2000), and ALS (Karlsson et al., 2004; Keep et al., 2001; Kirkinezos et al., 2004).

More specific evidence for a pathogenic role of $\mathrm{mPT}$ and CypD in neurological disorders has been obtained through genetic knockout studies. Animals lacking CypD have displayed increased resistance to cerebral ischemia, supporting the pharmacological studies using CypD inhibitors in different cerebral ischemia models (Schinzel et al., 2005). CypD deletion has also been found to be beneficial in animal models of multiple sclerosis and Alzheimer's disease (Du et al., 2008; Forte et al., 2007).

In contrast to the conclusions of pharmacological studies using CypD inhibitors in animal models of neurological 

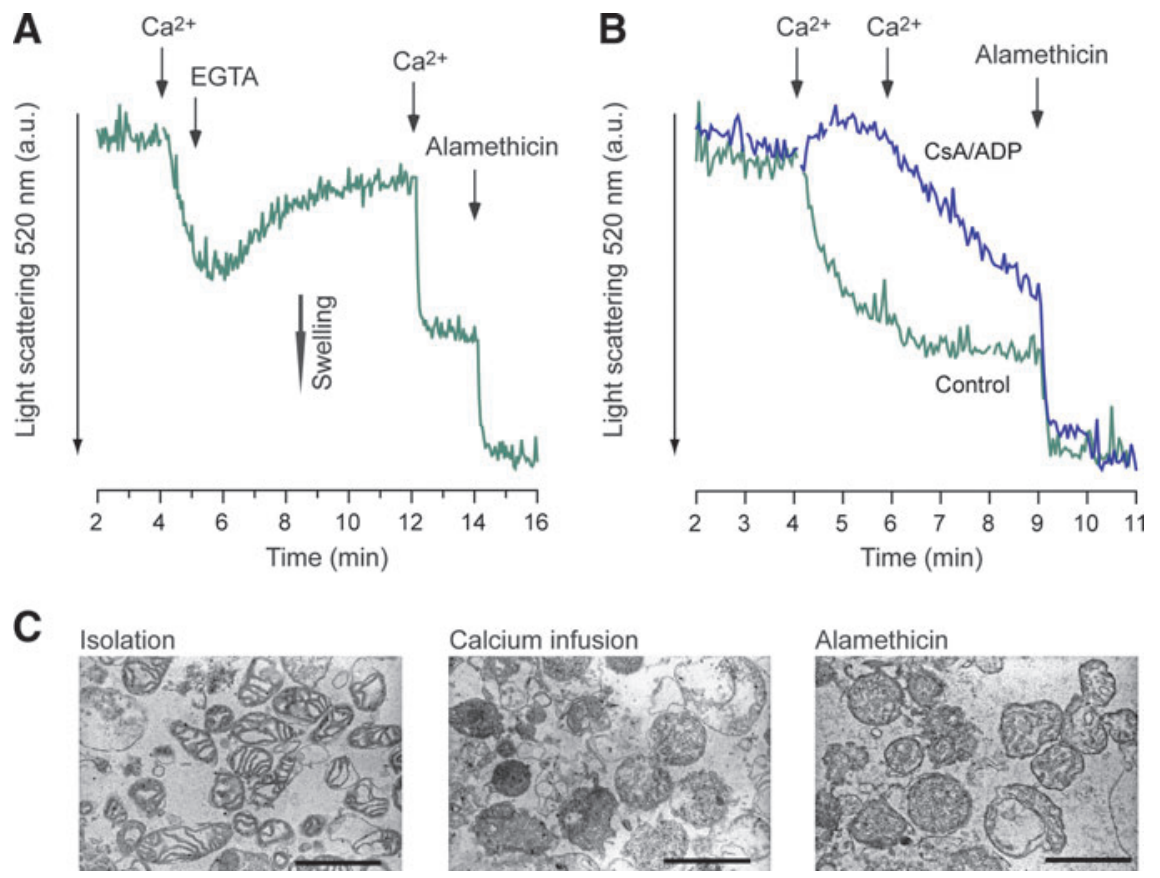

FIG. 5. Reversible calcium-induced $\mathrm{mPT}$ and inhibition of swelling by mPT inhibitors in human brain mitochondria. (A) Representative traces $(n=3)$ of reversible swelling in human brain mitochondria induced by $200 \mu \mathrm{M} \mathrm{Ca}^{2+}$, followed by $400 \mu \mathrm{M}$ of the $\mathrm{Ca}^{2+}$ chelator EGTA. Swelling was induced a second time by $\mathrm{Ca}^{2+}(1 \mathrm{mM})$, and mitochondria were then permeabilized by the non-specific ionophore alamethicin. (B) Representative traces $(n=2)$ of $\mathrm{Ca}^{2+}$-induced swelling with or without the presence of the endogenous $\mathrm{mPT}$ inhibitor ADP $(100 \mu \mathrm{M})$, and the cyclophilin D (CypD) inhibitor cyclosporin A (CsA; $1 \mu \mathrm{M}$ ). Mitochondria were challenged with two additions of $100 \mu \mathrm{M} \mathrm{Ca}^{2+}$, followed by exposure to alamethicin. (C) Electron micrographs of brain mitochondria following isolation, calcium infusion, and alamethicin exposure [scale bars $=1 \mu \mathrm{m}$; ADP, adenosine diphosphate; $\mathrm{mPT}$, mitochondrial permeability transition; EGTA, ethyleneglycol-bis- $(\beta$ aminoethylether)- $N, N, N^{\prime}, N^{\prime}$-tetraacetic acid; a.u., arbitrary units]. Color image is available online at www.liebertpub.com/neu.

disorders, several studies using isolated mitochondria have questioned a prominent role of $\mathrm{mPT}$ in the CNS. Brain mitochondria have been argued to be insensitive to $\mathrm{mPT}$ and swelling (Berman et al., 2000), or to be relatively resistant to mPT induction (Andreyev and Fiskum, 1999), and CsA has been suggested to be a less potent inhibitor of $\mathrm{MPT}$ in brain mitochondria compared to mitochondria from other organs (Brustovetsky and Dubinsky, 2000; Kristal and Dubinsky, 1997). Other studies have provided evidence and argued for a qualitatively and pharmacologically similar $\mathrm{mPT}$ phenomenon in rodent brain mitochondria to that in the more commonly studied heart and liver mitochondria (Chalmers and Nicholls, 2003; Hansson et al., 2004a). Further, it has been suggested that $\mathrm{CypD}$ is downregulated in the mature rodent brain (Eliseev et al., 2007). If CypD is downregulated in the adult human brain, there would be no rationale for using CypD inhibitors in patients with neurological disorders. Here we confirm the presence of CypD in human adult brain and liver mitochondria. Further, the CypD inhibitor CsA was found to have a significant effect on mitochondrial CRC, a quantitative assay for $\mathrm{mPT}$, in adult human brain as well as liver mitochondria.

Induction of $\mathrm{mPT}$ is transient when inducing factors are removed in vitro (Hunter and Haworth, 1979b). Reversible mPT-mediated swelling has previously been demonstrated in rodent brain mitochondria (Hansson et al., 2004a), and reversible mPT-dependent remodeling of mitochondria has also been described in cultured hippocampal neurons in models of excitotoxicity (Shalbuyeva et al., 2006). Using in vivo imaging with two-photon microscopy, loss of mitochondrial membrane potential has been demonstrated to occur within 1-3 min of global cerebral ischemia. The mitochondrial dysfunction was recovered rapidly upon reperfusion, and was blocked by CsA, indicating that $\mathrm{mPT}$ activation is an early reversible event that could trigger delayed cell death (Liu and Murphy, 2009). Previous studies support this conclusion, as mitochondria have been demonstrated to accumulate calcium shortly after ischemia (Zaidan and Sims, 1994), and to undergo transient swelling following ischemia (Petito and Pulsinelli, 1984). Moreover, early CsA administration following reperfusion prevents early Cyt c release, and dramatically reduces delayed neuronal cell death in animals subjected to global ischemia (Domanska-Janik et al., 2004; Uchino et al., 1998). As demonstrated here, mPT activation and swelling are reversible events in human brain mitochondria, supporting the conclusion drawn from animal studies of reversible $\mathrm{mPT}$ in the pathogenesis of delayed neuronal death in cerebral ischemia.

As stated above, there is extensive documentation of a neuroprotective effect of CsA in different animal models of TBI. The shear forces will cause an immediate, but also a delayed, cellular injury and disruption of the BBB (Buki and Povlishock, 2006). In contrast to other neurological indications, $\mathrm{mPT}$ inhibition can be achieved in brain parenchyma via systemic CsA administration, due to the disruption of the BBB. Promising animal data have influenced two independent groups to initiate NIH-sponsored human clinical trials of 
CsA administration to patients with severe TBI in the United States. The initial studies in patients with TBI show that CsA is well tolerated, enters the CNS, and demonstrates a dose-related improvement in favorable outcome (Hatton et al., 2008; Mazzeo et al., 2008, 2006). Although mPT inhibition may not be the only target for CsA, these clinical trials in TBI, as well as the promising effect of CsA against myocardial reperfusion injury (Mewton et al., 2010; Piot et al., 2008), are the first human studies testing the hypothesis of $\mathrm{mPT}$-mediated injury in human disease.

The major challenge of the present study was to obtain viable brain tissue and viable mitochondria for functional analyses. Therefore, it was not feasible to address all aspects of $\mathrm{mPT}$ in brain mitochondria. Further, brain tissue samples were derived from patients with neurological conditions requiring neurosurgery (Table 1), and it is unknown how these acute conditions may affect the evaluation of $\mathrm{MPT}$ and expression of CypD. In summary, we have provided evidence that human brain and liver mitochondria possess a CypDsensitive permeability transition. Taking the limitations mentioned above into account, the findings presented here support the rationale of $\mathrm{CypD}$ inhibition as a pharmacological target in patients with acute neurological damage and chronic neurodegenerative disease.

\section{Acknowledgments}

This study was supported by the Swedish Research Council (reference no. 2008-2634), by the Japanese Ministry of Health, Labour and Welfare grant no. 18591724, and the Foundation of the Swedish National Board of Health and Welfare. The authors are grateful to Hitoshi Miura, Takashi Ogata, Hiroshi Nishioka, Tetsuo Ishizaki, Tomohiro Nomura, Mamoru Murakami, Shingo Ohno, Hiroyuki Jinbo, and Hitoshi Izawa for support in obtaining tissue samples. D-MeAla ${ }^{3} \mathrm{EtVal}^{4}$-cyclosporin (Debio-025) was kindly provided by Debiopharm S.A.

\section{Author Disclosure Statement}

E.E. is co-founder and officer, and M.J.H. is a stockholder of Maas Biolab, LLC, and NeuroVive Pharmaceutical AB (publ), which hold intellectual property rights and develop the use of cyclosporins as cyclophilin D inhibitors for neurological treatment. The other authors have nothing to disclose.

\section{References}

Alcala, S., Klee, M., Fernandez, J., Fleischer, A., and PimentelMuinos, F.X. (2008). A high-throughput screening for mammalian cell death effectors identifies the mitochondrial phosphate carrier as a regulator of cytochrome c release. Oncogene 27, 44-54.

Andreyev, A., and Fiskum, G. (1999). Calcium induced release of mitochondrial cytochrome $\mathrm{c}$ by different mechanisms selective for brain versus liver. Cell Death Differ. 6, 825-832.

Baines, C.P., Kaiser, R.A., Purcell, N.H., Blair, N.S., Osinska, H., Hambleton, M.A., Brunskill, E.W., Sayen, M.R., Gottlieb, R.A., Dorn, G.W., Robbins, J., and Molkentin, J.D. (2005). Loss of cyclophilin D reveals a critical role for mitochondrial permeability transition in cell death. Nature 434, 658-662.

Baines, C.P. (2010). The cardiac mitochondrion: nexus of stress. Annu. Rev. Physiol. 72, 61-80.
Basso, E., Fante, L., Fowlkes, J., Petronilli, V., Forte, M.A., and Bernardi, P. (2005). Properties of the permeability transition pore in mitochondria devoid of cyclophilin D. J. Biol. Chem. 280, 18558-18561.

Bauer, M.K., Schubert, A., Rocks, O., and Grimm, S. (1999). Adenine nucleotide translocase-1, a component of the permeability transition pore, can dominantly induce apoptosis. J. Cell Biol. 147, 1493-1502.

Berman, S.B., Watkins, S.C., and Hastings, T.G. (2000). Quantitative biochemical and ultrastructural comparison of mitochondrial permeability transition in isolated brain and liver mitochondria: evidence for reduced sensitivity of brain mitochondria. Exp. Neurol. 164, 415-425.

Bernardi, P., Krauskopf, A., Basso, E., Petronilli, V., BlalchyDyson, E., Di Lisa, F., and Forte, M.A. (2006). The mitochondrial permeability transition from in vitro artifact to disease target. FEBS J. 273, 2077-2099.

Brustovetsky, N., and Dubinsky, J.M. (2000). Limitations of cyclosporin A inhibition of the permeability transition in CNS mitochondria. J. Neurosci. 20, 8229-8237.

Brustovetsky, N., and Klingenberg, M. (1996). Mitochondrial $\mathrm{ADP} / \mathrm{ATP}$ carrier can be reversibly converted into a large channel by $\mathrm{Ca} 2+$. Biochemistry $35,8483-8488$.

Buki, A., and Povlishock, J.T. (2006). All roads lead to disconnection?-Traumatic axonal injury revisited. Acta Neurochir. (Wien.) 148, 181-193; discussion 193-184.

Buki, A., Okonkwo, D.O., and Povlishock, J.T. (1999). Postinjury cyclosporin A administration limits axonal damage and disconnection in traumatic brain injury. J. Neurotrauma 16, 511521.

Chalmers, S., and Nicholls, D.G. (2003). The relationship between free and total calcium concentrations in the matrix of liver and brain mitochondria. J. Biol. Chem. 278, 9062-19070.

Cook, A.M., Whitlow, J., Hatton, J., and Young, B. (2009). Cyclosporine A for neuroprotection: establishing dosing guidelines for safe and effective use. Expert Opin. Drug Saf. 8, 411419.

Crompton, M., Ellinger, H., and Costi, A. (1988). Inhibition by cyclosporin A of a Ca2+-dependent pore in heart mitochondria activated by inorganic phosphate and oxidative stress. Biochem. J. 255, 357-360.

Domanska-Janik, K., Buzanska, L., Dluzniewska, J., Kozlowska, H., Sarnowska, A., and Zablocka, B. (2004). Neuroprotection by cyclosporin A following transient brain ischemia correlates with the inhibition of the early efflux of cytochrome $\mathrm{C}$ to cytoplasm. Brain Res. Mol. Brain Res. 121, 50-59.

Du, H., Guo, L., Fang, F., Chen, D., Sosunov, A.A., McKhann, G.M., Yan, Y., Wang, C., Zhang, H., Molkentin, J.D., GunnMoore, F.J., Vonsattel, J.P., Arancio, O., Chen, J.X., and Yan, S.D. (2008). Cyclophilin D deficiency attenuates mitochondrial and neuronal perturbation and ameliorates learning and memory in Alzheimer's disease. Nat. Med. 14, 1097-1105.

Eliseev, R.A., Filippov, G., Velos, J., VanWinkle, B., Goldman, A., Rosier, R.N., and Gunter, T.E. (2007). Role of cyclophilin D in the resistance of brain mitochondria to the permeability transition. Neurobiol. Aging 28, 1532-1542.

Empey, P.E., McNamara, P.J., Young, B., Rosbolt, M.B., and Hatton, J. (2006). Cyclosporin A disposition following acute traumatic brain injury. J. Neurotrauma 23, 109-116.

Forte, M., Gold, B.G., Marracci, G., Chaudhary, P., Basso, E., Johnsen, D., Yu, X., Fowlkes, J., Bernardi, P., and Bourdette, D. (2007). Cyclophilin D inactivation protects axons in experimental autoimmune encephalomyelitis, an animal model of multiple sclerosis. Proc. Natl. Acad. Sci. USA 104, 7558-7563. 
Friberg, H., Ferrand-Drake, M., Bengtsson, F., Halestrap, A.P., and Wieloch, T. (1998). Cyclosporin A, but not FK 506, protects mitochondria and neurons against hypoglycemic damage and implicates the mitochondrial permeability transition in cell death. J. Neurosci. 18, 5151-5159.

Halestrap, A.P., and Davidson, A.M. (1990). Inhibition of $\mathrm{Ca} 2(+)$-induced large-amplitude swelling of liver and heart mitochondria by cyclosporin is probably caused by the inhibitor binding to mitochondrial-matrix peptidyl-prolyl cistrans isomerase and preventing it interacting with the adenine nucleotide translocase. Biochem. J. 268, 153-160.

Halestrap, A.P., and Pasdois, P. (2009). The role of the mitochondrial permeability transition pore in heart disease. Biochim. Biophys. Acta. 1787, 1402-1415.

Halestrap, A.P., Woodfield, K.Y., and Connern, C.P. (1997). Oxidative stress, thiol reagents, and membrane potential modulate the mitochondrial permeability transition by affecting nucleotide binding to the adenine nucleotide translocase. J. Biol. Chem. 272, 3346-3354.

Hansson, M.J., Mansson, R., Mattiasson, G., Ohlsson, J., Karlsson, J., Keep, M.F., and Elmer, E. (2004a). Brain-derived respiring mitochondria exhibit homogeneous, complete and cyclosporinsensitive permeability transition. J. Neurochem. 89, 715-729.

Hansson, M.J., Mansson, R., Morota, S., Uchino, H., Kallur, T., Sumi, T., Ishii, N., Shimazu, M., Keep, M.F., Jegorov, A., and Elmer, E. (2008). Calcium-induced generation of reactive oxygen species in brain mitochondria is mediated by permeability transition. Free Radic. Biol. Med. 45, 284-294.

Hansson, M.J., Mattiasson, G., Mansson, R., Karlsson, J., Keep, M.F., Waldmeier, P., Ruegg, U.T., Dumont, J.M., Besseghir, K., and Elmer, E. (2004b). The nonimmunosuppressive cyclosporin analogs NIM811 and UNIL025 display nanomolar potencies on permeability transition in brain-derived mitochondria. J. Bioenerg. Biomembr. 36, 407-413.

Hansson, M.J., Morota, S., Teilum, M., Mattiasson, G., Uchino, H., and Elmer, E. (2010). Increased potassium conductance of brain mitochondria induces resistance to permeability transition by enhancing matrix volume. J. Biol. Chem. 285, 741-750.

Hatton, J., Rosbolt, B., Empey, P., Kryscio, R., and Young, B. (2008). Dosing and safety of cyclosporine in patients with severe brain injury. J. Neurosurg. 109, 699-707.

Haworth, R.A., and Hunter, D.R. (1979). The Ca2+-induced membrane transition in mitochondria. II. Nature of the Ca2+ trigger site. Arch. Biochem. Biophys. 195, 460-467.

Hunter, D.R., and Haworth, R.A. (1979a). The Ca2+-induced membrane transition in mitochondria. I. The protective mechanisms. Arch. Biochem. Biophys. 195, 453-459.

Hunter, D.R., and Haworth, R.A. (1979b). The Ca2+-induced membrane transition in mitochondria. III. Transitional Ca2+ release. Arch. Biochem. Biophys. 195,468-477.

Karlsson, J., Fong, K.S., Hansson, M.J., Elmer, E., Csiszar, K., and Keep, M.F. (2004). Life span extension and reduced neuronal death after weekly intraventricular cyclosporin injections in the G93A transgenic mouse model of amyotrophic lateral sclerosis. J. Neurosurg. 101, 128-137.

Keep, M., Elmér, E., Fong, K.S., and Csiszar, K. (2001). Intrathecal cyclosporin prolongs survival of late-stage ALS mice. Brain Res. 894, 327-331.

Kirkinezos, I.G., Hernandez, D., Bradley, W.G., and Moraes, C.T. (2004). An ALS mouse model with a permeable bloodbrain barrier benefits from systemic cyclosporine A treatment. J. Neurochem. 88, 821-826.

Kokoszka, J.E., Waymire, K.G., Levy, S.E., Sligh, J.E., Cai, J., Jones, D.P., MacGregor, G.R., and Wallace, D.C. (2004). The
ADP / ATP translocator is not essential for the mitochondrial permeability transition pore. Nature 427, 461-465.

Kristal, B.S., and Dubinsky, J.M. (1997). Mitochondrial permeability transition in the central nervous system: induction by calcium cycling-dependent and -independent pathways. J. Neurochem. 69, 524-538.

Kroemer, G., Galluzzi, L., and Brenner, C. (2007). Mitochondrial membrane permeabilization in cell death. Physiol. Rev. 87, 99163.

Kuznetsov, A.V., Schneeberger, S., Seiler, R., Brandacher, G., Mark, W., Steurer, W., Saks, V., Usson, Y., Margreiter, R., and Gnaiger, E. (2004). Mitochondrial defects and heterogeneous cytochrome c release after cardiac cold ischemia and reperfusion. Am. J. Physiol. Heart Circ. Physiol. 286, H1633H1641.

Leung, A.W., Varanyuwatana, P., and Halestrap, A.P. (2008). The mitochondrial phosphate carrier interacts with cyclophilin $\mathrm{D}$ and may play a key role in the permeability transition. J. Biol. Chem. 283, 26312-26323.

Liu, R.R., and Murphy, T.H. (2009). Reversible cyclosporin Asensitive mitochondrial depolarization occurs within minutes of stroke onset in mouse somatosensory cortex in vivo: a twophoton imaging study. J. Biol. Chem. 284, 36109-36117.

Mansson, R., Morota, S., Hansson, M.J., Sonoda, I., Yasuda, Y., Shimazu, M., Sugiura, A., Yanagi, S., Miura, H., Uchino, H., and Elmer, E. (2010). Minocycline sensitizes rodent and human liver mitochondria to the permeability transition: implications for toxicity in liver transplantation. Hepatology (Baltimore) 51, 347-348; author reply 349-350.

Martin, L.J., Gertz, B., Pan, Y., Price, A.C., Molkentin, J.D., and Chang, Q. (2009). The mitochondrial permeability transition pore in motor neurons: involvement in the pathobiology of ALS mice. Exp. Neurol. 218, 333-346.

Matsumoto, S., Friberg, H., Ferrand-Drake, M., and Wieloch, T. (1999). Blockade of the mitochondrial permeability transition pore diminishes infarct size in the rat after transient middle cerebral artery occlusion. J. Cereb. Blood Flow Metab. 19, 736-741.

Mazzeo, A.T., Alves, O.L., Gilman, C.B., Hayes, R.L., Tolias, C., Niki Kunene, K., and Ross Bullock, M. (2008). Brain metabolic and hemodynamic effects of cyclosporin A after human severe traumatic brain injury: a microdialysis study. Acta Neurochir. (Wien.) 150, 1019-1031; discussion 1031.

Mazzeo, A.T., Kunene, N.K., Gilman, C.B., Hamm, R.J., Hafez, N., and Bullock, M.R. (2006). Severe human traumatic brain injury, but not cyclosporin a treatment, depresses activated $\mathrm{T}$ lymphocytes early after injury. J. Neurotrauma 23, 962-975.

Mbye, L.H., Singh, I.N., Carrico, K.M., Saatman, K.E., and Hall, E.D. (2009). Comparative neuroprotective effects of cyclosporin A and NIM811, a nonimmunosuppressive cyclosporin A analog, following traumatic brain injury. J. Cereb. Blood Flow Metab. 29, 87-97.

Mewton, N., Croisille, P., Gahide, G., Rioufol, G., Bonnefoy, E., Sanchez, I., Cung, T.T., Sportouch, C., Angoulvant, D., Finet, G., Andre-Fouet, X., Derumeaux, G., Piot, C., Vernhet, H., Revel, D., and Ovize, M. (2010). Effect of cyclosporine on left ventricular remodeling after reperfused myocardial infarction. J. Am. Coll. Cardiol. 55, 1200-1205.

Millay, D.P., Sargent, M.A., Osinska, H., Baines, C.P., Barton, E.R., Vuagniaux, G., Sweeney, H.L., Robbins, J., and Molkentin, J.D. (2008). Genetic and pharmacologic inhibition of mitochondrial-dependent necrosis attenuates muscular dystrophy. Nat. Med. 14, 442-447.

Morota, S., Mansson, R., Hansson, M.J., Kasuya, K., Shimazu, M., Hasegawa, E., Yanagi, S., Omi, A., Uchino, H., and Elmer, 
E. (2009). Evaluation of putative inhibitors of mitochondrial permeability transition for brain disorders-Specificity vs. toxicity. Exp. Neurol. 218, 353-362.

Nakagawa, T., Shimizu, S., Watanabe, T., Yamaguchi, O., Otsu, K., Yamagata, H., Inohara, H., Kubo, T., and Tsujimoto, Y. (2005). Cyclophilin D-dependent mitochondrial permeability transition regulates some necrotic but not apoptotic cell death. Nature 434, 652-658.

Nicholls, D.G. (2009). Mitochondrial calcium function and dysfunction in the central nervous system. Biochim. Biophys. Acta. 1787, 1416-1424.

Petito, C.K., and Pulsinelli, W.A. (1984). Delayed neuronal recovery and neuronal death in rat hippocampus following severe cerebral ischemia: possible relationship to abnormalities in neuronal processes. J. Cereb. Blood Flow Metab. 4, 194-205.

Petronilli, V., Costantini, P., Scorrano, L., Colonna, R., Passamonti, S., and Bernardi, P. (1994). The voltage sensor of the mitochondrial permeability transition pore is tuned by the oxidation-reduction state of vicinal thiols. Increase of the gating potential by oxidants and its reversal by reducing agents. J. Biol. Chem. 269, 16638-16642.

Piot, C., Croisille, P., Staat, P., Thibault, H., Rioufol, G., Mewton, N., Elbelghiti, R., Cung, T.T., Bonnefoy, E., Angoulvant, D., Macia, C., Raczka, F., Sportouch, C., Gahide, G., Finet, G., Andre-Fouet, X., Revel, D., Kirkorian, G., Monassier, J.P., Derumeaux, G., and Ovize, M. (2008). Effect of cyclosporine on reperfusion injury in acute myocardial infarction. N. Engl. J. Med. 359, 473-481.

Russmann, S., Kullak-Ublick, G.A., and Grattagliano, I. (2009). Current concepts of mechanisms in drug-induced hepatotoxicity. Curr. Med. Chem. 16, 3041-3053.

Schinzel, A.C., Takeuchi, O., Huang, Z., Fisher, J.K., Zhou, Z., Rubens, J., Hetz, C., Danial, N.N., Moskowitz, M.A., and Korsmeyer, S.J. (2005). Cyclophilin D is a component of mitochondrial permeability transition and mediates neuronal cell death after focal cerebral ischemia. Proc. Natl. Acad. Sci. USA 102, 12005-12010.

Shalbuyeva, N., Brustovetsky, T., Bolshakov, A., and Brustovetsky, N. (2006). Calcium-dependent spontaneously revers- ible remodeling of brain mitochondria. J. Biol. Chem. 281, 37547-37558.

Sims, N.R., and Anderson, M.F. (2008). Isolation of mitochondria from rat brain using Percoll density gradient centrifugation. Nature Protocols 3, 1228-1239.

Sullivan, P.G., Rabchevsky, A.G., Hicks, R.R., Gibson, T.R., Fletcher-Turner, A., and Scheff, S.W. (2000). Dose-response curve and optimal dosing regimen of cyclosporin A after traumatic brain injury in rats. Neuroscience 101, 289-295.

Tsuji, A., Tamai, I., Sakata, A., Tenda, Y., and Terasaki, T. (1993). Restricted transport of cyclosporin A across the blood-brain barrier by a multidrug transporter, P-glycoprotein. Biochem. Pharmacol. 46, 1096-1099.

Uchino, H., Elmér, E., Uchino, K., Li, P.A., He, Q.P., Smith, M.L., and Siesjö, B.K. (1998). Amelioration by cyclosporin A of brain damage in transient forebrain ischemia in the rat. Brain Res. 812, 216-226.

Waldmeier, P.C., Zimmermann, K., Qian, T., Tintelnot-Blomley, M., and Lemasters, J.J. (2003). Cyclophilin D as a drug target. Curr. Med. Chem. 10, 1485-1506.

Yoshimoto, T., and Siesjö, B.K. (1999). Posttreatment with the immunosuppressant cyclosporin A in transient focal ischemia. Brain Res. 839,283-291.

Zaidan, E., and Sims, N.R. (1994). The calcium content of mitochondria from brain subregions following short-term forebrain ischemia and recirculation in the rat. J. Neurochem. 63, 1812-1819.

Zoratti, M., and Szabo, I. (1995). The mitochondrial permeability transition. Biochim. Biophys. Acta. 1241, 139-176.

Address correspondence to: Magnus J. Hansson, M.D., Ph.D. Mitochondrial Pathophysiology Unit Laboratory for Experimental Brain Research Department of Clinical Sciences Lund University SE-221 84, Lund, Sweden

E-mail: magnus.hansson@med.lu.se 
